\title{
Syndicated RSS Feeds for Course Information Distribution
}

\author{
Ronald J. Glotzbach \\ Purdue University \\ West Lafayette, IN, USA
}

rjglotzbach@purdue.edu

\author{
Dorina A. Mordkovich \\ Purdue University \\ West Lafayette, IN, USA
}

dmordkovich@gmail.com

\section{Jaime E. Radwan \\ Incredible Technologies \\ Arlington Heights, IL, USA}

\section{jradwan@itsgames.com}

\section{Executive Summary}

Students in higher education today are technologically savvy and expect faculty to use myriad web technologies for course delivery. This includes taking advantage of email, course web sites, and online learning communities. However, expectations now also include RSS, blogs, we b-, pod-, and vod-casting, extending the classroom experience to provide active learning materials anytime, anywhere, and in multiple modalities. This contribution out lines the novel use of RSS technology for a course announcement system at Purdue University that aids IT educators without expense or significant time consumption. It begins by describing RSS technology and discussing the different possibilities for RSS within the classroom. It also describes the specific RSS application for real-time course announcements, detailing its creation and implementation. The classroom chosen for this study was one that begins to mirrorthe real world with its many sources of information. The addition of RSS feeds to the course website allowed the students to share information with their classmates, professor, and their real-world clients.

Initial $(n=53)$ and secondary $(n=29)$ questionnaires were given to the students in order to evaluate the usefulness and effectiveness of implementing RSS feeds in the classroom. In comparing the results students showed a significant increase in perceived knowledge ( $\mathrm{p}$-value $=$ $0.0017)$ and proficiency $(\mathrm{p}$-value $<0.0001)$ with RSS feeds and their potential to use this offered technology. The researchers also found that, although only $55.2 \%$ of users indicated using a RSS feed for other sources, $65.5 \%$ indicated using the course RSS feed, suggesting students found value in the RSS technology applied in

Material published as part of this publication, either on-line or in print, is copyrighted by the Informing Science Institute. Permission to make digital or paper copy of part or all of these works for personal or classroomuse is granted without fee provided that the copies are not made or distributed for profit or commercial advantage AND that copies 1) bear this notice in full and 2) give the full citation on the first page. It is permissible to abstract these works solong as credit is given. To copy in all other cases or to republish or to post on a serveror to redistribute to lists requires specific permission and payment of a fee.Contact Publisher@.InformingScience.org to request redistribution permission. the classroom setting.

Although there was evidence that students used the course RSS feed, the ttest comparing students' usage of RSS feeds between the initial and secondary questionnaires failed to yield a significant result. The researchers attribute this to a lack of a common method for all course announcements, ones made by 
students, professors and related third parties, to be distributed to the student.

This study found that including a RSS feed as part of the course created opportunities for further research into the effective use of RSS feeds in education. For IT educators in need of a costeffective solution for disseminating course information, this approach can be implemented with minimaltime or resources.

Keywords: RSS, quantitative research, t-test, e-Learning, web-based learning.

\section{Introduction to RSS}

While the concept for RSS emerged in 1997 with the release of channels in Microsoft's Internet Explorer 4.0 browser, the first version of RDF Site Summary (RSS) emerged in 1999. It is also identified by several other names including Really Simple Syndication, Rich Site Summary, Realtime Simple Syndication, and others.

While it has suffered from "the name game," like many XML-based technologies, it has been comparatively slow to grab a practical foothold on the Web. Although many news and advertising sites are now using RSS for real-time distribution, the base of consumers receiving RSS feeds remains primarily early adopters. A 2005 Yahoo white paper, RSS-Crossing into the Mainstream, described a study conducted by Ipsos Insight with over 4,000 participants. The study concluded that even though $12 \%$ of users are aware of RSS, only $4 \%$ actually use it (Grossnickle, Board, Pickens, \& Bellmont, 2005). However, the generation who grew up on computer technology is now quickly adding to the base of people receiving RSS feeds. In fact, according to the Pew Internet \& American Life Project (2005), 12\% of Internet users in the United States aged 18 to 29 already have a working knowledge of what the term RSS means. Additionally the Ipsos Insight study found that $27 \%$ of participants consume RSS syndicated pages without knowing what RSS is (Grossnickle et al., 2005). This could help explain the sudden growth in the number of RSS feeds across the web. According to BusinessWeek Online ("RSS keeps booming", 2005), the number of RSS feeds grew from 307,000 in January of 2004 to over 13 million in August of 2005. This is more than 20 times the number of new feeds emerging during the same period. A SlashDot survey (Hrastnik, 2005) predicted that RSS would continue to grow dramatically in the coming years. Today, RSS is very nearly ubiquitous on the Web.

As an Internet technology, RSS is most widely used for the instant organization and distribution of a wide variety of information that is available on the World Wide Web (WWW). Asmus, Bonner, Esterhay, Lechner, and Rentfrow (2005) comment that due to the simple and easy-to-use interface, RSS has become an essential web publishing vehicle. RSS works by allowing content distribut ors to syndicate brief snippets of content and post it as a RSS (XML) file on the Web. Most RSS files include a title, brief description, and a link where the user can follow-up to retrieve the "full-story." Those who wish to receive RSS content use special applicat ions called RSS a ggregators to "subscribe" to RSS feeds. Once subscribed to a feed, the consumer is immediately notified in some manner when a new item is added to a RSS feed by its publisher. In this way, RSS feeds provide an active information mechanism on the Web whereby consumers can know immediately of distributors' information, rather than having to constantly return to a web site for recently released information.

There are a variety of standalone RSS aggregators, and some browsers, such as Mozilla Firefox and Internet Explorer 7, include RSS functions within them. It should also be noted that RSS consumption is not limited to desktop applications alone - PDAs, cell phones, and other wireless devices can be set up to receive RSS feeds. Its ability to deliver short news messages in text-only format makes it the most efficient content delivery method for small screen devices (Joly, 2006). While the original goals of RSS may be loftier, the de facto use for RSS feeds has become a mechanism for creating content summaries of web sites to which users subscribe and receive noti- 
Glotzbach, Mordkovich, Radwan

fication. Passivity is the biggest limitation of web sites - users must access the site to see what is new. RSS, one of many technologies that provide an active method for attract ing traffic and individual consumer attention, is gaining popularity for this specific purpose.

\section{Classroom Need}

Although RSS feeds were initially utilized by readers to create individualized, syndicated news pages (Asmus et al., 2005), their increasing popularity has brought the potential opportunities to the attention of educators. According to Joly (2006), a number of colleges and universit ies have already integrated RSS feeds into school websites. RSS allows schools to effect ively disseminate important information to all students, regardless of individual schedules or how students prefer to receive it. For example, Duke University created Duke Today, a RSS powered and customizable news web portal. The application not only distributes news in law, medicine, and science, but it also includes "daily updates on everything from menus to computer security alerts" (Joly, 2006). The University of Utah explored the potential of RSS as an alternative to email when they created the school's online calendar. Addit ionally, The University of Iowa uses RSS to announce job openings, and The University of Alabama uses RSS for updates on catalogued materials in their library system (Joly, 2006).

RSS feeds can serve several uses in a variety of educational settings and provide technologydriven students with a plethora of opportunities to individualize their plans of study. With the content published in RSS feeds being immediately available to those with Internet connections with a few clicks (West, Wright, Gabbitas, \& Graham, 2006), the possibilities for RSS in classrooms are endless. From the distribution of course related materials to keeping up-to-date with new research related to the course topics, RSS feeds give students and educators alike the ability to skim the newest and most relevant content quickly (Cold, 2006). IT educators are always looking for a breakthrough in technology that increases classroom productivity, but are often deterred by the amount of time it would take to implement or by the cost of the technology / solution (Gillard, Bailey, \& Nolan, 2008). The solution discussed here requires no additional cost, assuming the course already has a web site and web space. Additionally, the time to implement is minimal while it enhances productivity and communication both inside and out side the classroom for IT educators.

One of the most popular uses of RSS feeds in educational settings is to enable and improve student research. With the ability to gather multiple sources on one page and perform targeted searches, RSS can be a powerful research tool aiding educators and students in performing indepth research with a few simple clicks (Asmus et al., 2005). It allows students to conduct their research as both individuals and collaboratively by sharing and combining feeds across various sources and encourages the sharing of information (Cold, 2006). A properly set up RSS feed aids the research process by notifying subscribers and saving the most recent post ing of information and current events. They have been compared to conduct ing research 24 hours a day for seven days a week, only the RSS feed is doing all of the work forthe researcher (Richardson, 2005).

The use of RSS feeds in a classroom also allows for a more collaborative learning environment and enhances communication between educators and students, as well as between the students themselves, creating new net works of knowledge. Having a variety of resources available in one, easy to use location, RSS encourages sharing among peers and creat es large repositories of knowledge that can benefit all users and subscribers (D'Souza, 2006). RSS feeds can keep track of discussions and conversation topics, wikis, newsgroups, interests, and web site updates, as well as build connections with others who have similar interests. The combination of all of these items helps students to build a deeper understanding of the presented concepts and enhance their comprehension of the materials above and beyond what is offered in the classroom, creating more dynamic learning (West et al., 2006). 
The ability of RSS to provide single-click access to the most current information eliminates the student's need to visit the required web sites regularly and increases their productivity by cutting down on search times for relevant subjects and news. This technology is also ideal for sharing classroom news, announcements, and updates so that students have easy access to the provided information, creating "personalized learning objects" for each class (D'Souza, 2006). Like all web sites, course web sites suffer from passivity. Educators who use the Web for content distribution would say that student attention and motivation is more difficult to obtain due to the hectic schedules many of them have. While most instructors post announcements to their course web sites, it is questionable how many students actually come to the web site to read the announcements and how many of them actually read the announcements once there.

The use of online materials and their ability to be available to students any time, any place, provides a novel opportunity for course instructors to appeal to all students no matter their learning style (Hardaway \& Will, 1997). Carver, Howard, and Lane (1999) note that students learn through a variety of learning styles, each as different and unique as the students themselves. This is not a new concept within the classroom, and by creating adaptive materials instructors can aid more students in comprehending the presented materials. Using adaptive hypermedia in a course, such as hypert ext, helps support a variety of learning styles including verbal, sequential, global, and sensing (Carver et al., 1999). Traditional classroom and laboratory instruction periods have systematic and, sometimes, dry approaches in order to cover the necessary materials in the time period allowed. The use of hypertext provides learners who may have a difficult time adapting to the traditional methods the ability to review the mat erials out side of the classroom. The ability to jump around within the content, explore areas that need to be clarified, or examine hierarchical structure allows students to comprehend the content more efficiently and effectively (Carver et al., 1999).

With the new abilities course instructors have to incorporate technology and online elements into course work, they also have the ability to present new and significant opport unities for students to improvetheir educational experience and environment (Hardaway \& Will, 1997). Through the use of multimedia tools like RSS, instructors are providing students with access to classroom materials online that allows them to replay the overall classroom experience. This helps to extend the students' learning beyond the time spent within the classroom or laboratory setting with the instructors, furthering their knowledge and ability to comprehend what has been presented to them. These multimedia tools also serve as excellent ancillary materials by allowing students to catch up on assignments and missed work due to poor attendance or poor note taking (Hardaway \& Will, 1997).

A study conducted by Carver et al. (1999) found that students are more likely to use the hypermedia tools that are provided to them to further their learning if those tools are available out side of the classroom and in their home environments. Hypermedia tools that require additional equipment or software that is only available in the classroom environment are often avoided by students and are rated poorly in their usefulness to enrolled students (Carver et al., 1999). Tools like RSS feeds are available to students through the use of the same web browsers they use to browse the web or check their email. With no additional soft ware or equipment being needed, students can personalize their RSS feeds and experiences to fit their needs and individual learning styles.

\section{Guidelines for RSS Implementation in a Classroom}

West et al. (2006) developed a list of guidelines for implement ing RSS technologies in the classroom after studying its effectiveness in their pre-service instructional technology course. West et al. recommend that the instructor define a purpose for implementing a new technology in the course before the semester starts. The content of the course could then be structured around that 
new technology. In addition, even though the students in their study had previously been enrolled in technology courses, many of them found the new technology to be a challenge. To combat this problem West et al. recommended using simple, user friendly tools. Finally, the study concluded that, even though their students became proficient with the technology, they did not understand how the technology could help them achieve their learning goals. To help the students, the first few weeks of the semester should be dedicated to overcoming the technological barriers of using the newtechnology, and then afterwards, the students can tackle the conceptual learning curve. After the first few weeks, the instruct ors need to re-evaluate student progress and further assist students with any problems they might be having. It is also helpful for the instructor to demonstrate the proper usage of the technology and continue using it throughout the semester (West et al., 2006).

\section{RSS Course Announcement System}

The following portion of this paper details the specifics of the RSS system created by the authors. The system includes both the interface components as viewed in the browser, as well as the ASP scripts that were used to modify the RSS (XML) file.

\section{The Course Announcement RSS Document}

A RSS document is written in a consistent and repetitive format that aggregators and feed readers can easily parse into useful headlines. Figure 1 shows the frozen structure of a RSS 2.0 document.

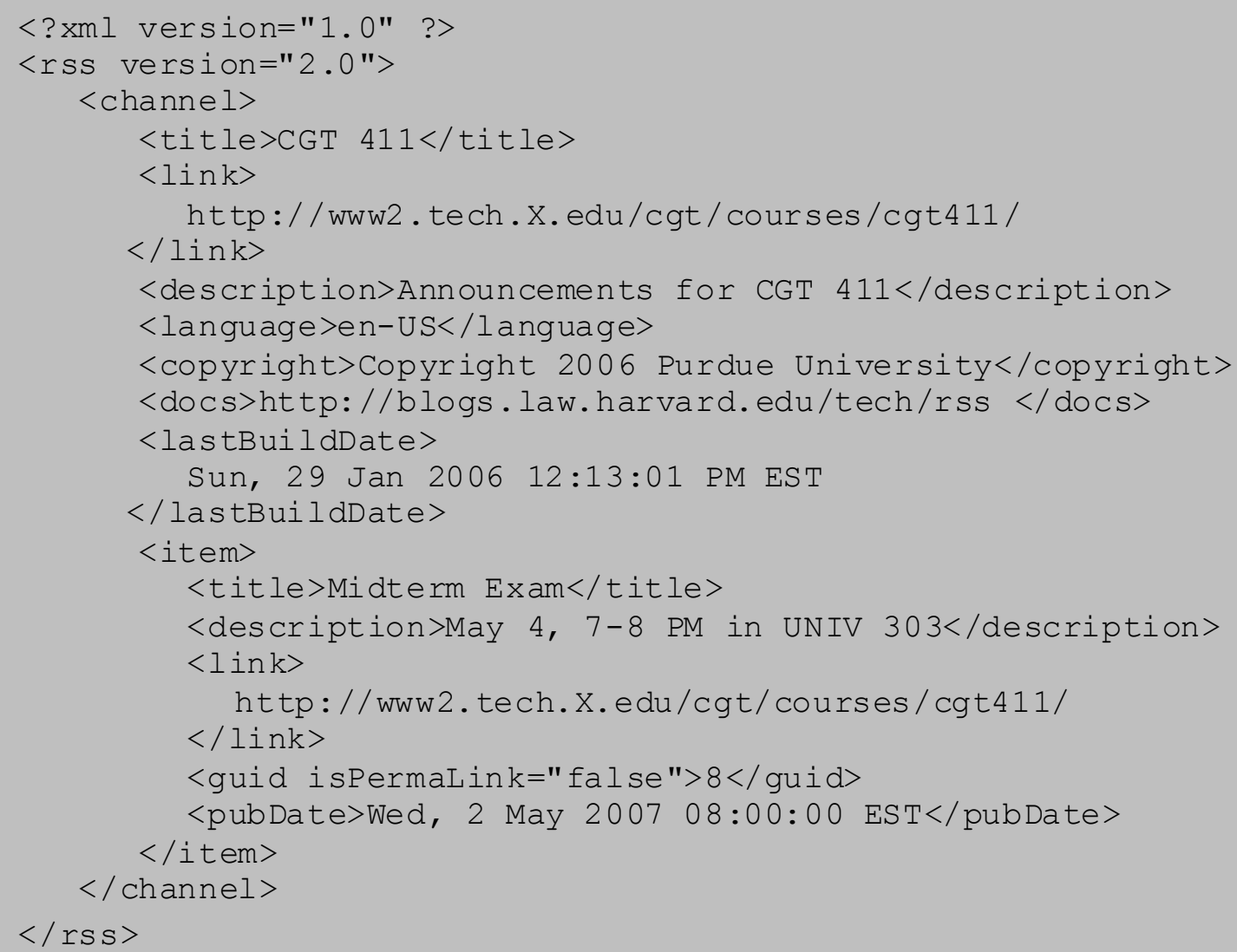

Figure 1. A RSS 2.0 document from the course management system. 


\section{Displaying the RSS feed on the Course Home Page}

While a minor part of the system, the authors desired to be able to have the announcements that were in the RSS feed display in the browser as shown in Figure 2. To accomplish this, ASP code was included in the course home page as shown in Figure 3.

The root, or document, element of a RSS file is the $<$ rss $>$ element that includes the version attribute and associated " 2.0 " value. Nested inside the document element is one $<$ channel $>$ element that contains all necessary sub-elements, including the it ems that make up the feed headlines. As noted by Hammersley (2005) and Orchard (2005), three elements are required inside the $<$ channel $>$ element: $\triangleleft$ title $>,<$ link $>$, and $<$ description $>$.

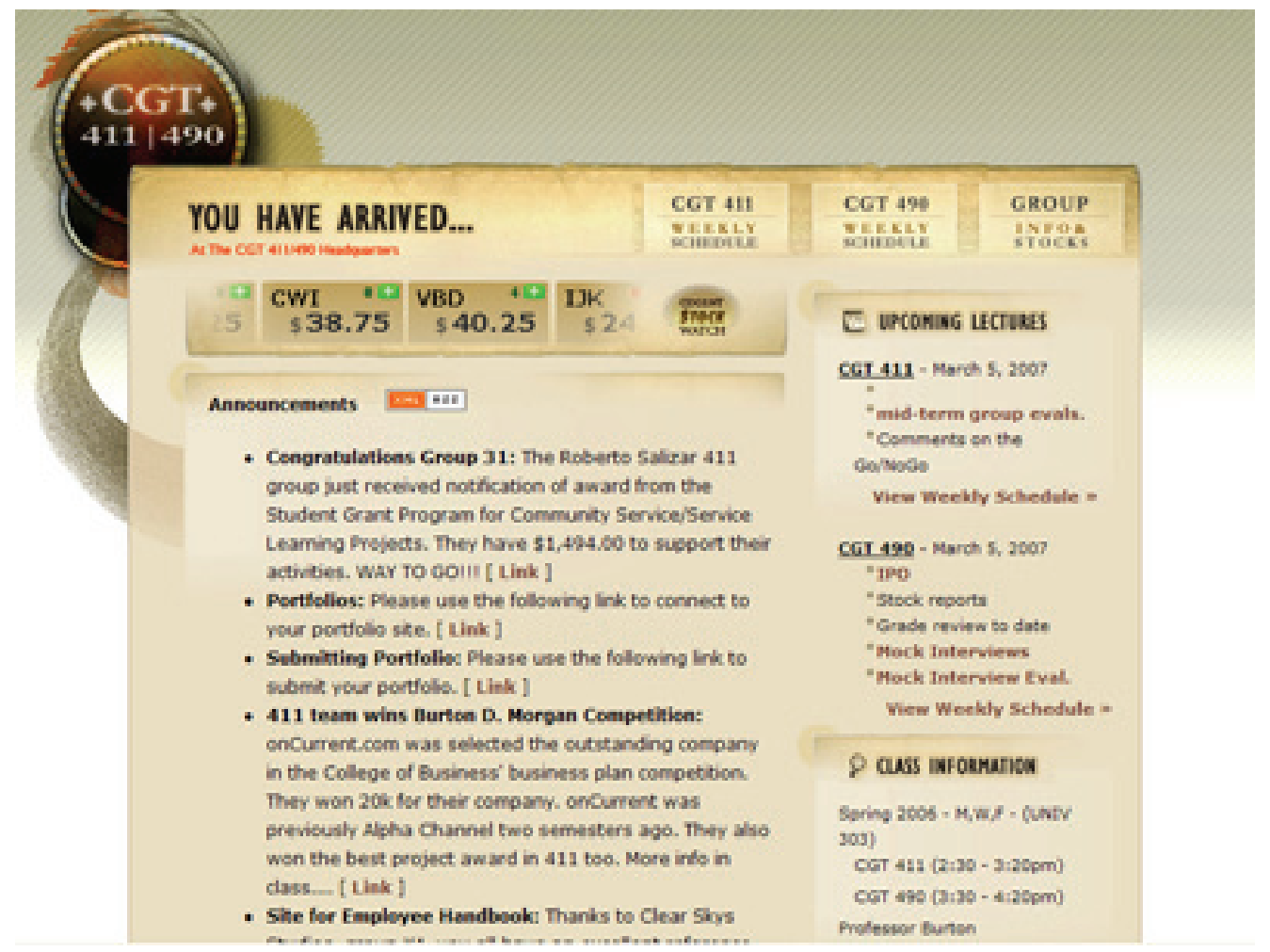

Figu re 2. Ann oun cements are integrated from the RSS feed in to the course home page. 


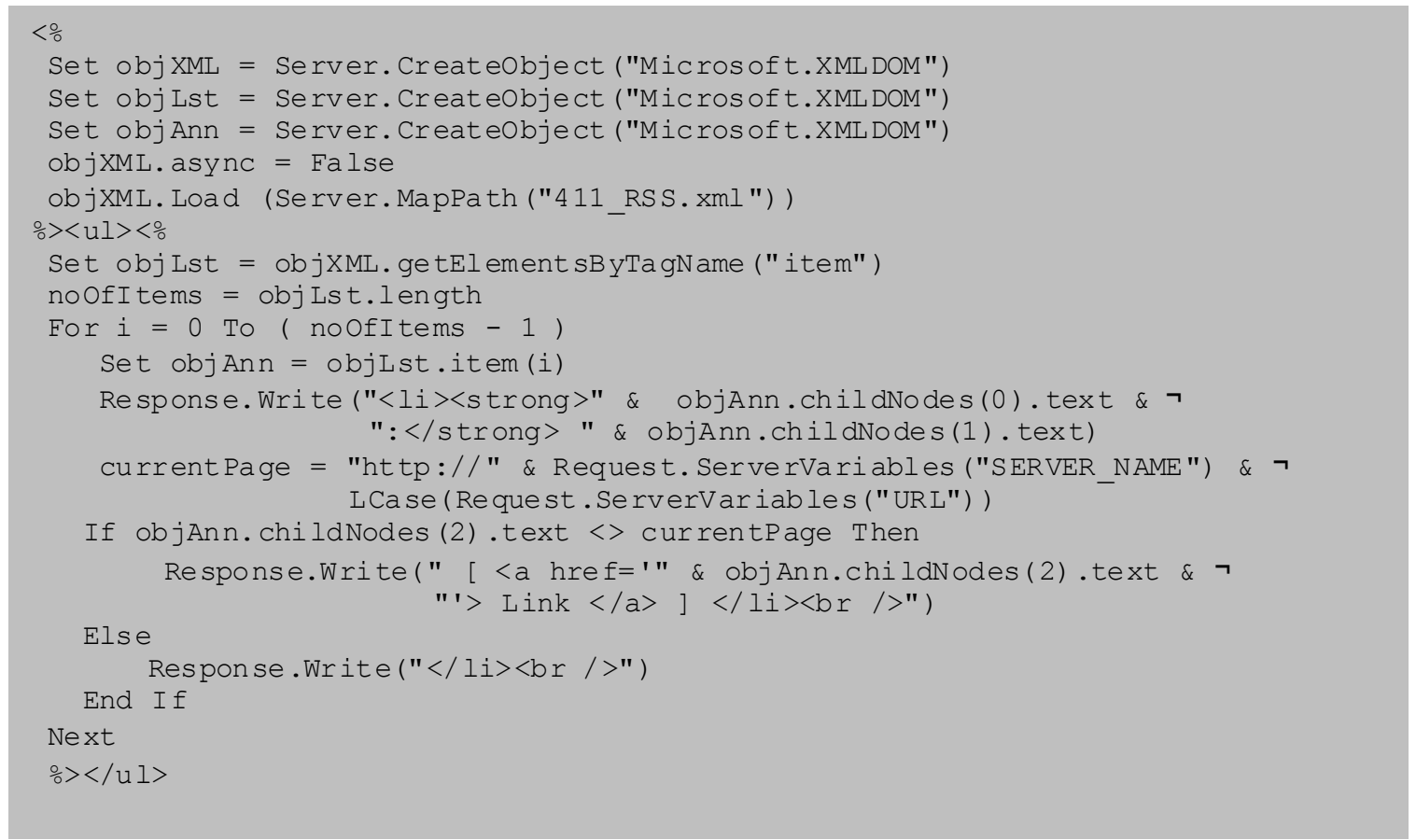

Figu re 3. ASPCode to extract the RSS items and write them into the cou rse home page.

\section{UI for Editing the RSS Feed}

To edit the RSS feed for each course, there were two HT ML pages. The authors designed this system so that other faculty could use it and would not have to know how to write RSS (XML) or other web code. Figure 4 shows the initial interface screen for editing the RSS feed items.

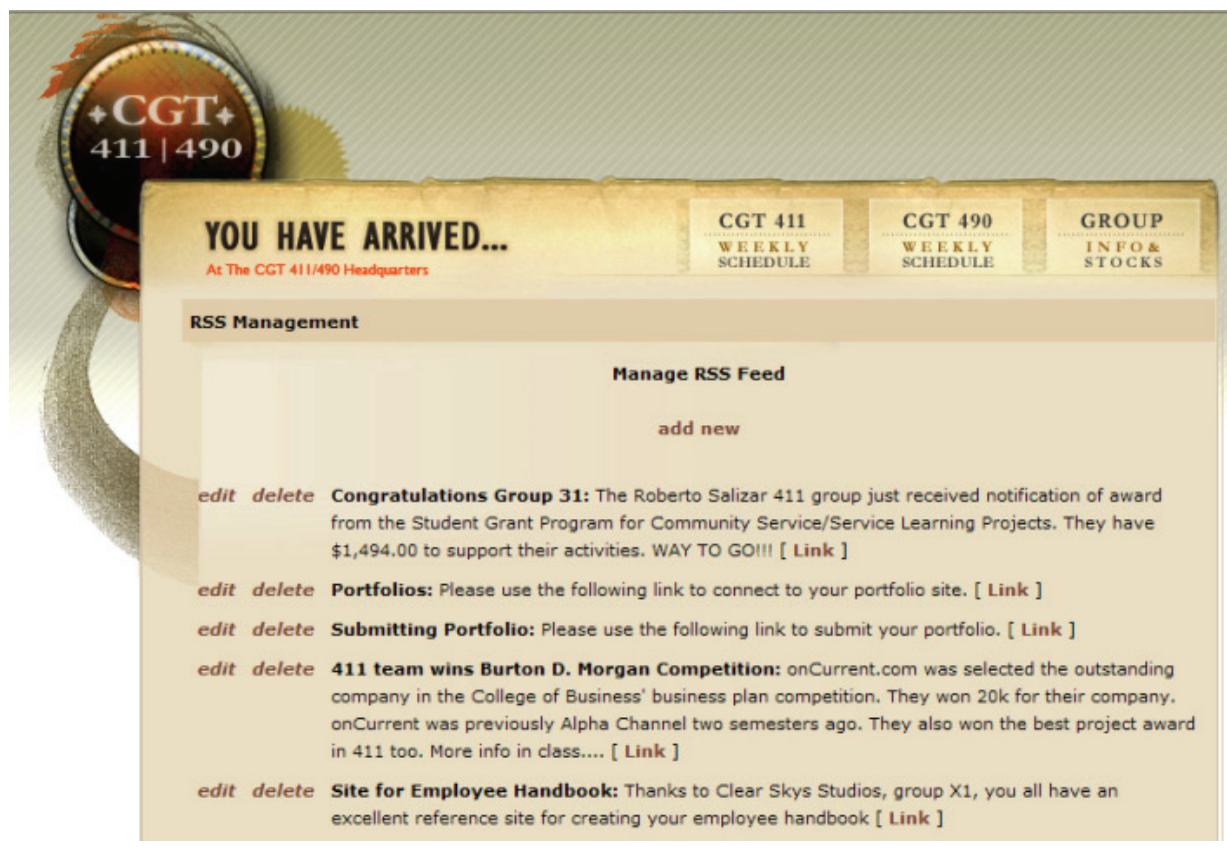

Figu re 4. The user chooses to edit, dele te or add a new feeditem via an HTML page. 


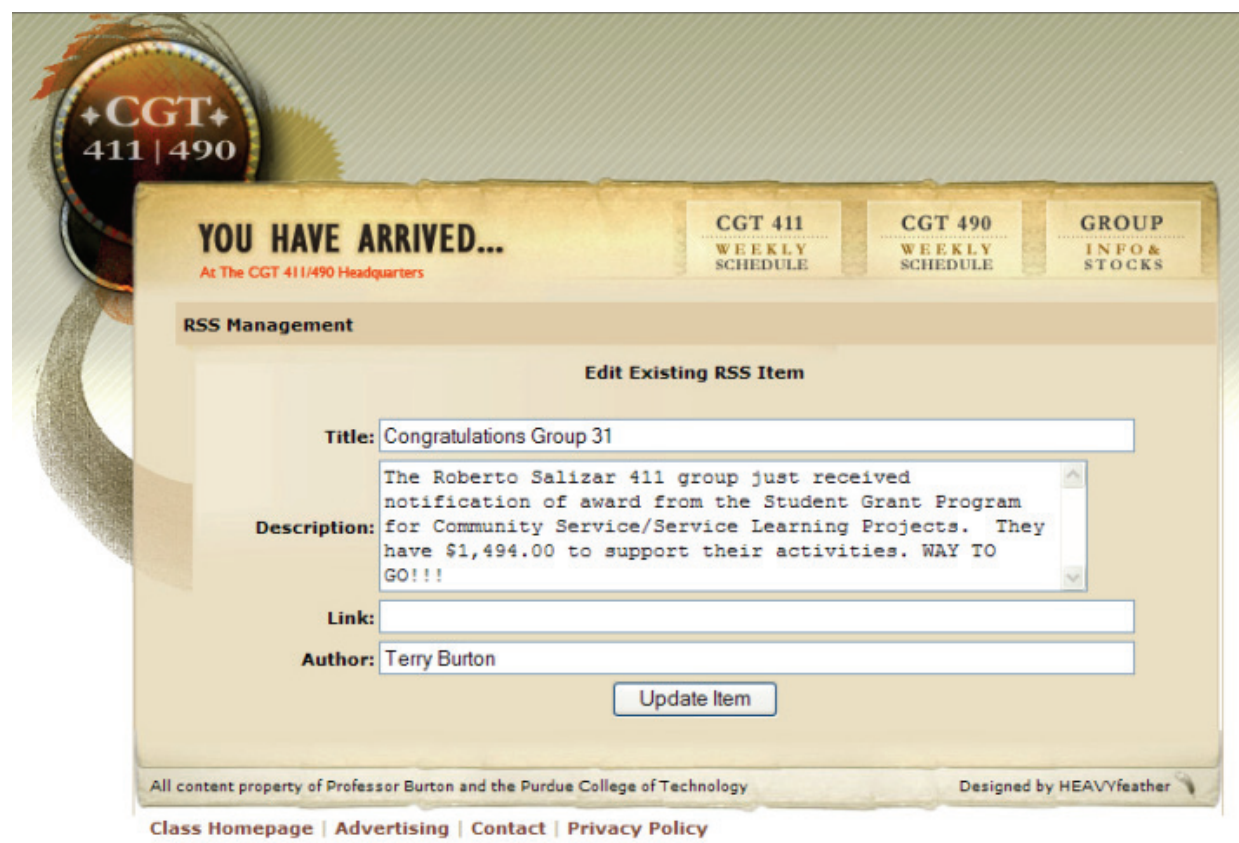

Figu re 5: An HTML form is presented if the use $r$ chooses to e dit a specific feed item.

From this page the user can add, modify, or delete items in the feed. If users choose to edit a feed item, they are presented a form as shown in Figure 5. If they choose to delete an existing feed item, they are prompted to ensure they wish to delete it. If they choose to add a new item, they are presented an empty form similar to that shown in Figure 4. Both of the interface screens shown in Figures 4 and 5 use the same ASP script to manipulate the data. The screen shown in Figure 4 uses code similar to that shown in Figure 3 and thus will not be reviewed again. The code for taking the input from the form in Figure 5 and writ ing it into the RSS feed is describe $d$ in the next section.

\section{Building the Feed with ASP}

When a new item is added to the feed, the management application builds a memory-resident view of the RSS feed, appending the new item in sequence prior to the existing items, thus allowing aggregators to display the new item first in the list. Figure 6 demonstrat es this code. 


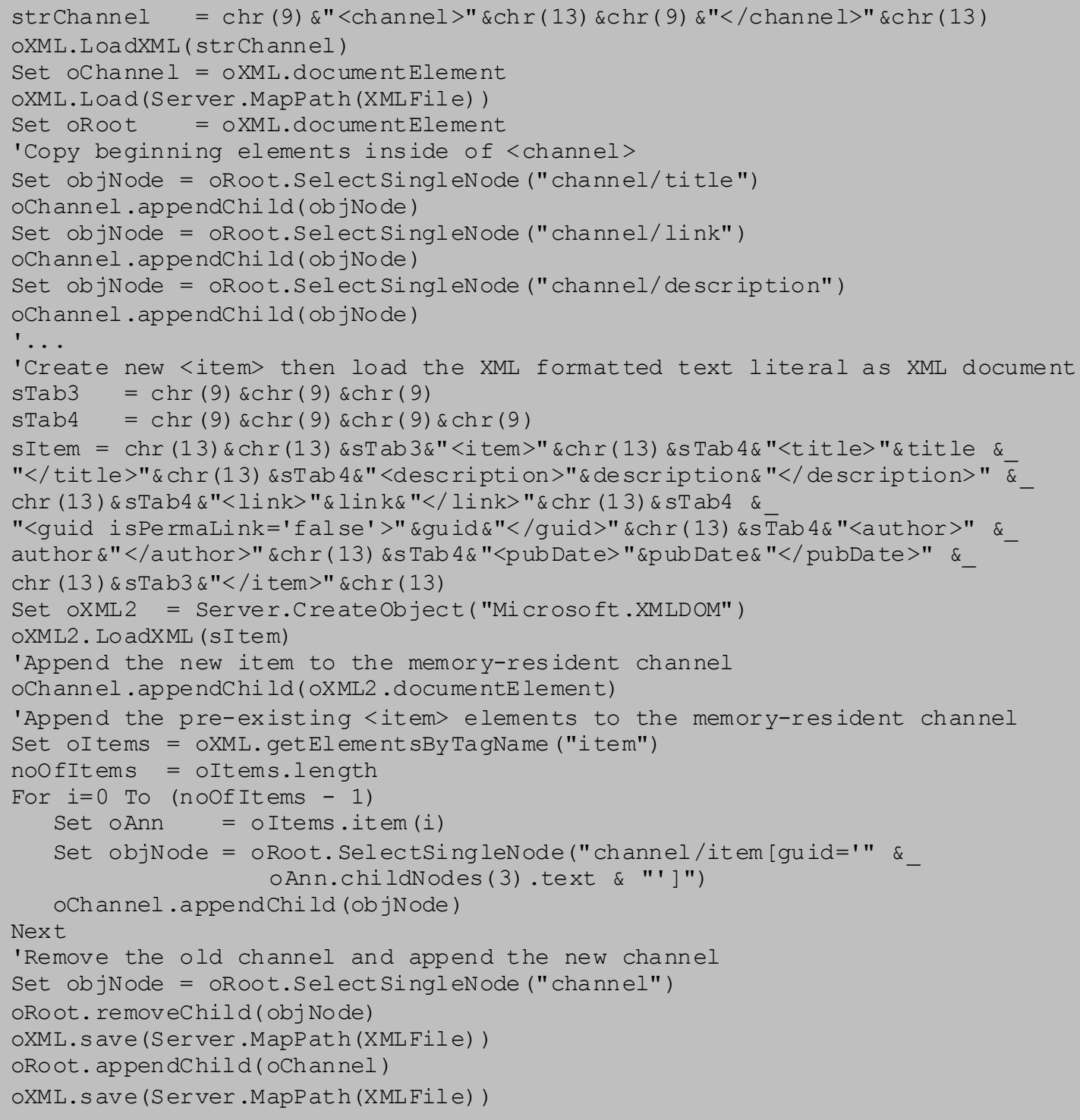

Figu re 6. Building the RSS feed in memory an d appen ding the channel.

The resulting RSS feed from Figure 6 contains the new $<$ item $>$ inserted within the existing channel as the first item in the list (compare to Figure 1). Formatting and indentation from the XML file are also preserved to ensure the document remains easy to read as a plain text document (see Figure 7). 


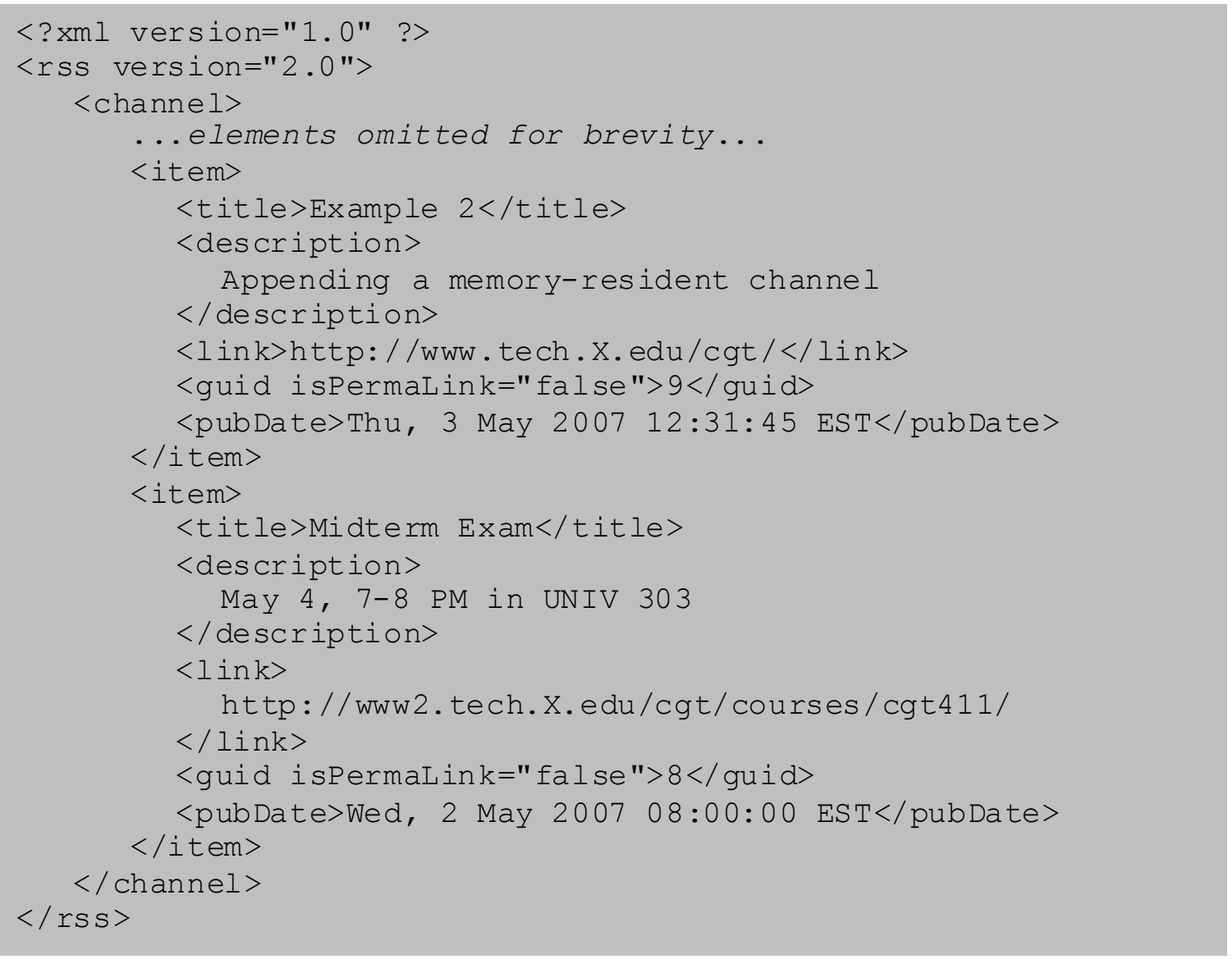

Figu re 7. The resul ting RSS feed with new item appen ded.

The following sections detail research conducted to determine the usefulness of the RSS system described above, as perceived by students at Purdue University.

\section{Methodology}

The methodology of the research consisted of designing and implementing pre- and post-use questionnaires that were used to evaluate the usefulness and effectiveness of int egrating RSS feeds into classroom setting.

Two studies were undertaken. A pilot study involved employing a RSS feed in a freshmen-level course at Purdue University in West Lafayette, Indiana. The selected course was CGT/C\&IT 141, a required course for all Computer Graphics T echnology (CGT) students, ent it led Internet Foundations, Technologies, and Development. At the beginning of the fall 2006 semester, the authors posted an online questionnaire to determine students' existing knowledge of RSS feeds and gather their thoughts on the potential benefits of implementing a RSS feed in the class. After the students completed the questionnaire, they were given a short introduction to RSS and its use within this particular classroom setting.

The CGT/C\&IT 141 RSS feed was made available to the students for the entire semester. At the conclusion of the fall 2006 semester, the authors posted a second online questionnaire, to determine the extended level of usefulness and effect iveness of the provided RSS feed for CGT/C\&IT 141 course announcements. Atotal of 133 students completed the initial questionnaire and 203 students, the secondary questionnaire. 
This specific course was chosen for two reasons; the topic of RSS feeds fits int o the course content, and there are large number of students enrolled in the course. However, CGT/C\&IT 141 is a course that has a limited number of announcements throughout the running of the semester, posting only a few announcements to the RSS feed every couple of weeks. Upon evaluating student responses, the researchers made a decision to carry out a full study in another course, one with a greater number of announcements.

The subjects chosen for the full study were students enrolled in CGT 411 at Purdue University in West Lafayette, Indiana. CGT 411, entitled Contemporary Problems in Applied Computer Graphics, is a required 400-level course for all Computer Graphics T echnology (CGT) seniors. It is a group-based course that "attempts to identify, design, qualify, manage, create and present a final project relative to existing or emerging issues within the discipline. Activities and experiences will explore related topics such as project planning and management, user expectations, interpersonal communications skill and quality management" (Purdue University, 2007). CGT 450, Applied Computer Graphics Professional Life Cycle, another required course that runs concurrently with CGT 411, attempts to "identify, design, qualify, manage, create and present a series of professional practice activities relative to the existing discipline of applied comput er graphics" (Purdue University, 2007). Students are required to enroll in both classes, CGT 411 and CGT 450 (hereafter referred to as CGT 411/450) in the same semester.

At the beginning of the spring 2007 semester, the authors posted an online questionnaire (seethe Appendix) to determine the level of usefulness and effectiveness of a RSS feed for the CGT $411 / 450$ course announcements. This initial questionnaire consisted of 18 quant it at ive and qualitative questions. The participants were asked a variety of questions regarding RSS feeds. Questions included, but were not limited to, whether or not participants were familiar with RSS feeds, how often they used RSS feeds, their personal perceived proficiency with RSS feeds, their individual feelings on RSS, and the use of RSS for the course in which they were enrolled. This questionnaire assumed that student participants were at the beginning of the course and had minimal exposure to the RSS feed used in CGT 411/450; however, because a number of professors in the department have integrated RSS into their course websites over the past several semesters, the authors expected the students to have some previous exposure to RSS technology. A total of 56 students successfully completed this questionnaire, 55 seniors and one graduate student. Of the sample, there were 9 females, or $16.1 \%$ of the participants, and 47 males, or $83.9 \%$ of participants.

At the conclusion of the spring 2007 semester, the authors posted a second online questionnaire to determine the extended level of usefulness and effectiveness of the provided RSS feed for CGT $411 / 450$ course announcements. In this secondary questionnaire participants were asked similar questions to those in the initial questionnaire regarding RSS feeds. These questions again included, and were not limited to, whether participants were familiar with RSS feeds, how often they used the RSS feed for this course, how often they used RSS feeds for other information and resources, their personal perceived proficiency with RSS feeds, their individual feelings on RSS, and the use of RSS for the course to which they were enrolled in. Students enrolled in this spring semester were exposed to the CGT 411/450 RSS feed for the entire semester. The same 56 students from the initial questionnaire, ages 18 to 29 , were also eligible to take part in the secondary questionnaire. Of those 56, 29 students successfully completed the questionnaire, which resulted in a response rate of $51.8 \%$. Again these students ranged in class levels from seniors to graduate students with 3 females, or $10.3 \%$ of the participants, and 26 males, or $89.7 \%$ of participants.

To ensure the validity of the measuring instruments used in the full study, the authors had previously met with professors in the Department of Stat istics and discussed the purpose of the questionnaire, the intention of each question, measurable outcomes of each question, and which statistical method to use. It was determined that the most appropriate statistical method to use to com- 
pare the student responses for the quant it ative questions between the initial and the secondary questionnaires of the full study was a t-test.

Once the data from the secondary questionnaire had been collected, the means and standard deviations were calculated for both questionnaires. A number of $t$-tests were then performed. These test s included a comparison of participants' perceived proficiency and knowledge of RSS technologies from the initial and secondary questionnaires and a comparison of frequency of usage of RSS feeds. For thet-tests performed, $\mu_{1}$ represented the initial questionnaire mean and $\mu_{2}$ represented the secondary questionnaire mean for the variable that was being analyzed. Therefore the null and alternate hypotheses were:

$$
\mathrm{H}_{\mathrm{o}}: \mu_{1}=\mu_{2} \quad \mathrm{H}_{\mathrm{a}}: \mu_{1} \neq \mu_{2}
$$

Finally a comparison of students' responses from the pilot (CGT/C\&IT 141) and full (CGT $411 / 450$ ) studies was conducted. The initial questionnaire of the pilot study was compared with the initial questionnaire of the full study and a similar comparison completed for the secondary questionnaires. These comparisons were not inferential in nature.

\section{Findings}

The following sections detail the findings from the initial and secondary questionnaires administered in the CGT/C\&IT 141 and the CGT 411/450 courses during the fall 2006 and spring 2007 semester at Purdue University. Given that the pilot study was performed on a freshman class and the full study was performed the following semester on a senior class that required senior standing in order to enroll, none of the participants were involved in both studies.

\section{Pilot Study}

Results from the initial CGT/C\&IT 141 questionnaire showed that just over onethird of the 133 participants, or 39\%, indicated that they had previous knowledge of what a RSS feed was. Additionally just over half, approximately $56 \%$, of those same students indicated that they had previously used a RSS feed to gather the important information they needed.

In comparing the results from the initial questionnaire to the secondary questionnaire, students showed an increased knowledge of RSS feeds and their potential to use this offered technology. The number of participants who indicated they underst ood the potential of RSS increased from $39 \%$ at the beginning of the class to $75 \%$ of the 203 participants by the end of the class. The $t$-test performed by the researchers, with a p-value between 0.025 and 0.01 , also showed a significant difference in student perceived proficiency in RSS technologies between the initial and secondary questionnaires.

The researchers found that the number of students who used RSS feeds increased between the initial and secondary questionnaires. A t-test, with a p-value less than 0.0005 , showed a significant difference in the number of students who used RSS feeds for both the course and other sources. However only $42 \%$ of the participants noted on the secondary questionnairethat they took advantage of the specific RSS feed that was provided as a resource for course announcements. The results from the pilot study were published as part of the SIGGRAPH 2007 annual conference (Glotzbach, Mohler, \& Radwan, 2007).

\section{Main Study}

After evaluat ing the results of the pilot study, the authors began the main study on CGT 411/450. The main study consisted of an initial questionnaire given at the beginning of the course and a secondary questionnaire given at the end of the course. The results were statistically analyzed and then some simple comparisons were made between the main study and the pilot study. 


\section{Initial CGT 411/450 questionnaire}

The responses indicated that $80.4 \%$ of the 56 students had previous knowledge of what a RSS feed was, however, only $46 \%$ of the students had previously used a RSS feed. Out of the students that used RSS feeds, approximately $37.5 \%$ indicated that they were using a RSS feed at least once per week. The majority of students also commented that they felt the RSS feed integrated into the course could be very beneficial.

\section{Secondary CGT $411 / 450$ questionnaire}

The results showed that all 29 participants who completed the secondary questionnaire indicated that they now underst ood what a RSS feed was. Additionally $79.3 \%$ of the participants indicated that they used the CGT 411/450 RSS feed to check for course announcements, with $65.5 \%$ of those participants indicating doing so at least once per week. Of the 29 participants, $52.2 \%$ indicated that they also regularly use other RSS feeds at least once per week to gather the important information they need from other resources.

Anecdotal data from the students in regard to the question, "Do you feel that the RSS feed was an effective means of communicating course announcements," included remarks such as "absolutely," "I believe it could be effective to people who are used to it," "most of the time, yes - but the course announcements don't encompass everything," and "I think it was effective, but I just needed to get used to checking the RSS feed before going to the homepage."

Additional anecdotal dat a from the students in regard to the question, "Would you recommend that other courses offer a RSS feed for course announcements in addition to traditional means?" included remarks such as "sure, a lot of people use it so I think there is a need for this type of technology in the classroom," "in addition to traditional means, yes, but not in place of," and "only if the teacher is willing to be responsible for keeping it up to date." Of the written comments provided by the students, 17 out of 28 of them on the final questionnaire were considered positive. Some students did not write anything, while other students wrote something but did not answer the question. Of the rest, the written comments pertained to the question asked and 24 out of 28 were considered useful.

\section{CGT 411/450 questionnaire comparisons}

Table 1 depicts the comparison of the variables that were measured as part of this study, providing the means, t-values, and p-values.

Table 1: Comparis on of the measu red variables

\begin{tabular}{|l|c|c|c|c|c|}
\hline MEASURED VARIABLES & DF & $\begin{array}{c}\text { INITIAL } \\
\text { Q UESTIONNAIRE } \\
\text { MEAN (n=56) }\end{array}$ & $\begin{array}{c}\text { SECONDARY } \\
\text { QUESTIONNAIRE } \\
\text { MEAN (n=29) }\end{array}$ & t-VALUE & P-VALUE \\
\hline $\begin{array}{l}\text { Perceived Pro fici ency in RSS } \\
\text { Technologies }\end{array}$ & 83 & 2.27 & 4.41 & 6.37 & $<.0001$ \\
\hline $\begin{array}{l}\text { Perceived Knowl edge of RSS } \\
\text { Feeds }\end{array}$ & 83 & 2.39 & 3.45 & 3.24 & 0.0017 \\
\hline Use of RSS Feeds & 83 & 2.57 & 3.29 & 1.66 & 0.1006 \\
\hline
\end{tabular}

The analysis from the participant data produced a t-value of 6.37 for perceived proficiency in

RSS technologies, which, with 83 degrees of freedom, yielded a p-value less than 0.0001 that was significant at the .01 alpha level. Therefore the null hypothesis $\left(\mathrm{H}_{\mathrm{o}}\right)$ was rejected since there was a significant difference shown between the participants perceived proficiency in RSS technologies by the completion of the study, thus the difference could not be ascribed to chance alone. 
The analysis from the participants' data produced a t-value of 3.24 for the participants' perceived knowledge of RSS feeds, which, with 83 degrees of freedom, yielded a p-value of .0017 that was significant at the .01 level. Therefore the null hypothesis $\left(\mathrm{H}_{\mathrm{o}}\right)$ was rejected since there was a significant difference shown between the participants use of RSS feeds by the completion of the study, thus the difference could not be ascribed to chance alone.

The analysis from the participants' data produced a t-value of 1.66 for the participants' use of RSS feeds, which, with 83 degrees of freedom, yielded a p-value of 0.1006 that did not prove to be significant at the .01 level. Therefore the alternative hypothesis $\left(\mathrm{H}_{\mathrm{a}}\right)$ was rejected since there was no significant difference shown between the participants use of RSS feeds by the completion of the study and as such, could be ascribed to chance alone.

\section{CGT 411/450 vs. CGT/C\&IT 141}

This comparison yielded some interesting data, although inferential tests were not conducted to see if any of the changes were statistically significant. The initial results in the spring 2007 questionnaire indicated that $80.4 \%$ of the 56 students had previous knowledge of what a RSS feed was, compared to only $39 \%$ of the 133 students in CGT/C\&IT 141 in 2006 . However, only 46\% of CGT 411/450 students had previously used a RSS feed, compared to $56 \%$ of the students in CGT/C\&IT 141. Additionally, approximately $37.5 \%$ of the CGT $411 / 450$ students indicat ed that they had used RSS at least once per week, compared to $27 \%$ of students in CGT/C\&IT 141. The majority of participants in both questionnaires also commented that they felt the RSS feed integrated into the course could be very beneficial.

In comparing the secondary questionnaire results in CGT 411/450 to CGT/C\&IT 141, the CGT $411 / 450$ study yielded a much higher percentage of students who indicated using the RSS feed for checking course announcements. Additionally, 79.3\% indicated using the RSS feed, with $65.5 \%$ of those students using it at least once per week. However, only 42\% of CGT/C\&IT 141 students indicating using the RSS feed for their course announcements. The students that did not use the feed indicated scarcity of important announcements and lack of RSS support in older browsers as the reason for doing so.

\section{Discussion}

Students find enjoyment in keeping up with the latest technology. However, IT instructors often see it as both a new way of teaching and learning, and as a significant financial, time, and energy investment (Gillard et al., 2008). The solution implemented in this research took into consideration all of the above concerns. Implementing a RSS feed did not require additional hardware or software. CGT/C\&IT 141 and CGT 411/450 already had existing course websites, thus it was only a matter of adding a couple of additional pages. Further, learning how to publish to the RSS feed, for the professor, and subscribing and using the feed, for the students, did not require extensive training. The results showed that with just a short introduction to the topic and simple demonstration of how to use it, students and the course instructor were able to comprehend the concept of RSS as it was presented to them.

Anecdotal responses collected in the pilot study during the fall 2006 semester indicat ed that scarcity of course announcements in CGT/C\&IT 141 did not make it an ideal course for this solution; therefore, the researchers chose to implement a second RSS feed in a different course where a large number of announcements had to be made at every class meeting.

Delivery of course announcements in this new fashion was regarded as a breakthrough in course information dissemination. Prior to the implementation of the RSS feed, course announcements were delivered in an age-old manner of verbally announcing them during class time. CGT $411 / 450$ is a capstone course requiring students in the course to work with real-world clients. Due 
to the involvement of outside parties, who at the beginning of the course only communicate with the course instructor, there are always many course announcements which used to take up a large portion of the allotted lecture time. With the implementation of the RSS feed, many course announcements were distributed to the students via the RSS feed prior to the class meeting. The web form created for management of the RSS feed made it easy for non-technologically savvy instructors to utilize an advanced technological solution that increased communication with students. The idea of transitioning course information delivery from a passive means to an active means resulted in generally positive reactions from both the students and faculty.

A consistent theme across the qualitative remarks written on the secondary CGT 411/450 questionnaire noted that the instruct or for the course must be actively involved in updating and maintaining the course announcements for them to be very effective - suggesting that if a professor were not diligent in maintaining the announcements, students might not check them either. These remarks support the result of thet-test used to compare the usage of RSS feeds between the initial and secondary questionnaire. The results of the test failed to show a significant difference between the overall usage of RSS feeds between the start and the end of the semester. This is a logical assessment, given that updatable material that remains static for a period of time becomes little more than a static web page and provides students with little incentiveto return frequently for updates. The researchers predict that a positive correlation would be seen between the frequency/number of announcements and the number of students who would take advantage of the RSS feed provided by the course.

In comparing the results from the initial CGT 411/450 questionnaire to the secondary questionnaire, students showed a significant increase in perceived knowledge and proficiency with RSS feeds and their potential to use this offered technology. These results showed that with just a short introduction and simple demonstration, students were able to comprehend the concept of RSS.

The researchers also found that although only $55.2 \%$ of users indicated using a RSS feed for other sources, $65.5 \%$ indicated using the CGT $411 / 450 \mathrm{RSS}$ feed, suggesting students found value in the RSS technology applied in the classroom setting. In addition, although the t-test performed by the authors show the difference was not statistically significant, the number of students who used RSS feeds increased between the initial and secondary questionnaires.

CGT 411/450 is unique in structure since the course instructor is not the sole source of announcements in the class. In this course, announcements can come from a variety of sources including the professor, the student groups, and third parties that are recruit ing the students to work on their projects. This could explain the lack of significance in the use of RSS feeds by the students between the initial and the secondary surveys. Although the RSS feed implemented in the course allowed the students to keep track of course announcements made by the course professor, it did not allow students to post and receive important course announcements from their peers and other involved parties.

\section{Recommendations for Future Work}

The seniors in the CGT 411/450 class are placed in groups based on their skills and the amount of interest in a certain project. These groups then become virtual companies that work with realworld clients on a variety of projects. Once the professors in the class approve the project, the virtual companies go "public" and begin offering stocks to the other companies in the class. The companies are also required to post a weekly news release highlight ing their progress with the project at hand, which then affects their stock values for that week. At the moment there is no permanent method for companies to post their news releases, nor to announce stock sales. The virtual company's only option is to speak to the ent ire class during regularly schedule course meetings to maketheir announcements, which uses valuable class time. Future work will involve 
implementing additional RSS feeds to allow the students themselves to disseminate important information concerning their groups or virtual companies.

The dynamic nat ure of CGT 411/450 makes it stand out from the typical lecture-based college courses. With the possibility of announcements coming from professors, student groups, or other involved parties, the classroom begins to mirror the real world with its many sources of information. Additional RSS feeds will allow the students to share the information with classmates and their real world clients in much the same way they share it among themselves.

\section{Conclusion}

This study found that including a RSS feed as part of the CGT 411/450 course created opport unities for further research into the effective use of RSS feeds in education. For IT educators in need of a cost-effective solution for disseminating course information, this approach can be implemented with minimal time or resources.

Data collected from the students indicated that, while they were using the RSS feed de signed to disseminate course announcements, there was no significant difference shown between the participants use of RSS feeds by the completion of the study and, as such, could be attributed to chance alone. However, students showed an increase in their perceived knowledge and proficiency with RSS feeds and their potential to use this offered technology.

This contribution has provided a novel implementation of RSS for course improvement. Future work in this area will focus on creat ing additional RSS feeds to allow students in the classroom to circulate important announcements about their groups to create a truly interactive classroom.

\section{References}

Asmus, J., Bonner, C., Esterhay, D., Lechner, A., \& Rentfrow, C. (2005). Instructional design technology trend analysis. Retrieved April 2, 2008 from http://elgg.net/collinb/files/1136/2967/TrendAnalysisWeb.pdf

Carver, C. A., Howard, R. A., \& Lane, W. D. (1999). Enhancing student learning through hypermedia coursew are and incorporation of student learning styles. IEEE Transactions on Education, 42(1), 3338.

Cold, S. J. (2006). Using Really Simple Syndication (RSS) to enhance student research. SIGITE Newsletter, 3(1), 6-9.

D'Souza, Q. (2006). RSS ideas for educators. Retrieved April 2, 2008 from http://www.teachinghacks.com/wpcontent/uploads/2006/01/RSS $\% 20$ Ideas $\% 20$ for $\% 20$ Edu cators $111 . \mathrm{pdf}$

Gillard, S., Bailey, D., \& Nolan, E. (2008). Ten reasons for IT educators to be early adopters of IT innovations. Journal of Information Technology Education, 7, 21-33. Retrieved from http://iite.org/documents/Vol7/JTTEv7p021-033Gillard257.pdf

Glotzbach, R. J., Mohler, J. L., \& Radwan, J. E. (2007). RSS as a course information delivery method. Proceedings of the ACM SIGGRAPH 2007 Annual Conference and Exposition.

Grossnickle, J., Board, T., Pickens, B., \& Bellmont, M. (2005). RSS_crossing into the mainstream. Retrieved February 19, 2008 from http://publisher.yahoo.com/rss/RSS whitePaper1004.pdf

Hammersley, B. (2005). Developing feeds with RSS and Atom. Sebastopol, CA: O’Reilly Media.

Hardaway, D., \& Will, R. P. (1997). Digital multimedia offers key to educational reform. Communications of the ACM, 40(4), 90-96.

Hrastnik, R. (2005). Slashdot survey predicts dramatic RSS growth, while RSS "wars" continue. Retrieved April 13, 2006 from 
http://rssdiary.marketingstudies.net/content/slashdot survey predicts dramatic rss growth while rss wars continue.php

Joly, K. (2006). RSS: The next big thing in university web communications. Retrieved February 19, 2008 from http://www.universitybusiness. com/viewarticle.aspx? articleid=44

Pew Internet \& American Li fe Project. (2005). Public awareness of internet terms. Retrieved April 2, 2008 from http://www.pewinternet.org/pdfs/PIP Data Techterm aware.pdf

Purdue University. (2007). CGT 411: Internet contemporary problems in applied computer graphics: course syllabus. Retrieved February 26, 2008 from http://www2.tech.purdue.edu/cgt/courses/cgt411

Orchard, L. M. (2005). Hacking RSS and Atom. Indianapolis, IN: Wiley Publishing.

Richardson, W. (2005). RSS: A quick start guide for educators. Retrieved April 2, 2008 from http://www.weblogg-ed.com/wp-content/uploads/2006/05/RSSFAQ4.pdf

RSS keeps booming. (2005, September 25). BusinessWeek Online. Retrieved April 2, 2008 from http://www.businessweek.com/technology/tech stats/rss050923.htm

West, R. E., Wright, G., Gabbitas, B., \& Graham, C. R. (2006). Reflections from the introduction of blogs and RSS Feeds into a preservice instructional technology course. TechTrends, 50(4), 54-60.

\section{Appendix: Questionnaires}

\section{Questionnaire \#1}

The objective of this questionnaire is to determine the level of usefulness and effectiveness a RSS feed for course announcements has for CGT 411. This questionnaire assumes that you are at the beginning of the course and have minimal exposure to the RSS feed used in CGT 411.

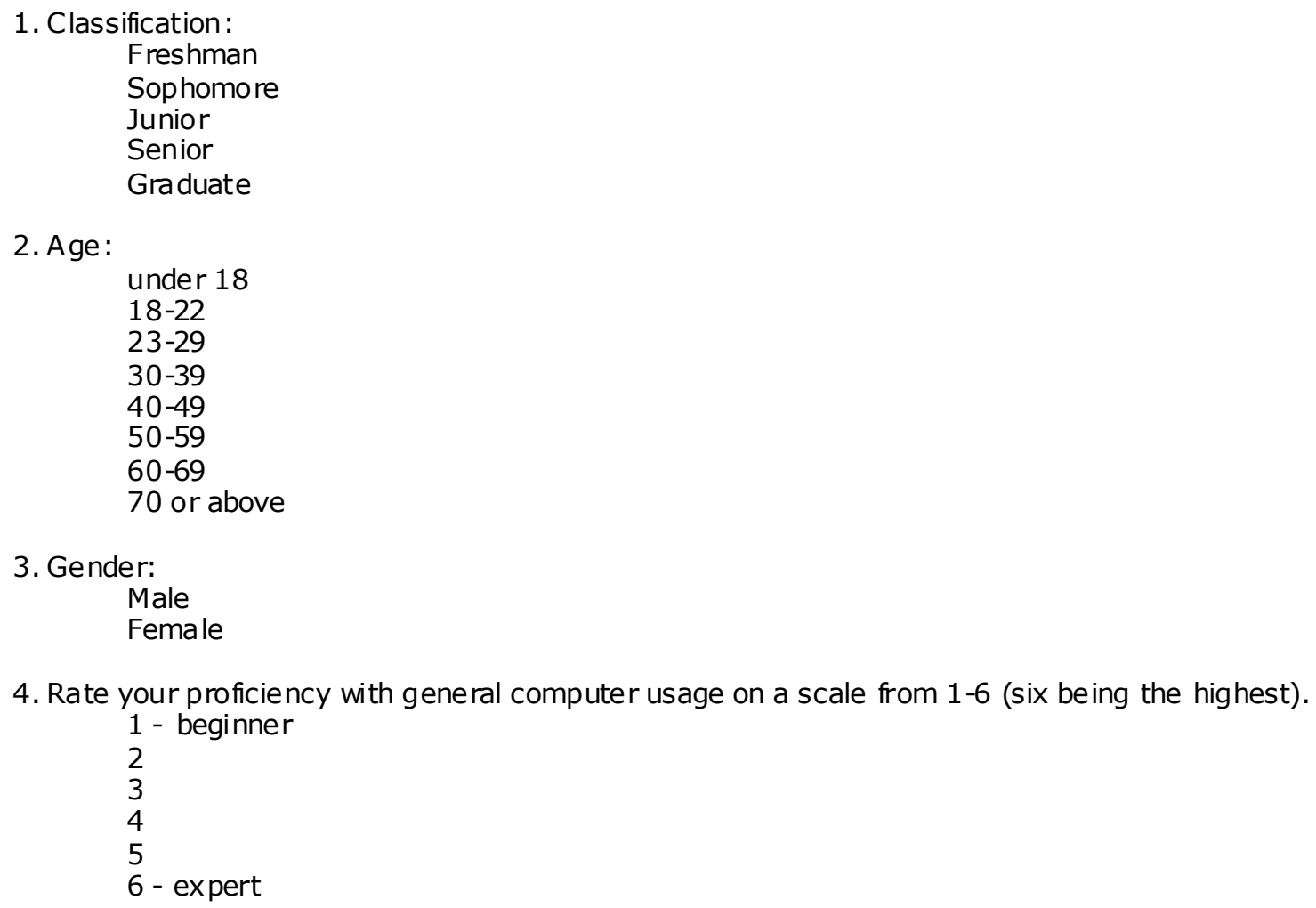

4. Rate your proficiency with general computer usage on a scale from 1-6 (six being the highest). 1 - beginner

2

3

4

5

6 - expert 
5. Rate your proficiency with Web-browsing and online technologies on a scale from 1-6 (six being the highest).

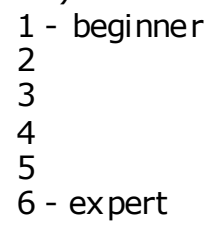

6. Have you used course Web sites in other courses here at Purdue (including WebCT)?

Yes

No

7. Where do you look for course announcements?

(limit: 500 characters or approximately 75 words)

8. Do you know what an RSS feed is?

Yes

No

9. Have you used an RSS feed before?

Yes

No

10. How often do you use RSS feeds?

Several time per day

Once per day

A few times per week

Once per week

Less than once per week

Never

11. Rate your prof iciency with RSS-related technologies on a scale from 1-6 (six being the highest).

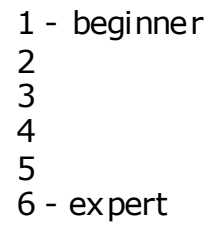

12. Rate your knowledge of RSS-related technologies on a scale from 1-6 (six being the highest)

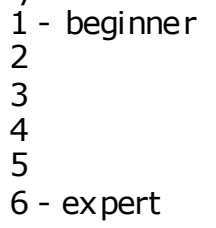

13. Rate the level of difficulty you have had using RSS feeds in the past on a scale from 1-6 (six being the highest)

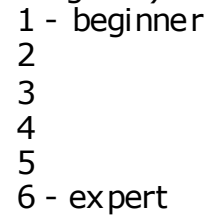

14. If you have used RSS feeds before, where did you use them (which sites )? (limit: 500 characters or approximately 75 words) 
15. What do you think about the integration of an RSS feed into this course? (limit: 500 characters or approximately 75 words)

16. Have you used RSS feeds in any other courses here at $X$ ? (limit: 500 characters or approximately 75 words)

17. Which do you prefer for checking course announcements, checking the course homepage or using an RSS feed?

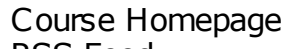

18. Is there a nother method, other than RSS feeds, that you would prefer for the delivery of course announcements? (limit: 500 characters or approximately 75 words)

\section{Questionnaire \#2}

The objective of this second questionnaire is to determine the level of usefulness and effectiveness an RSS feed for course announcements has for CGT 411 upon completion of the course.

1. Classification:
Freshman
Sophomore
Junior
Senior
Graduate
2. Age:
under 18
$18-22$
$23-29$
$30-39$
$40-49$
$50-59$
$60-69$
70 or above

\section{Gender: \\ Male \\ Female}

4. Rate your proficiency with general computer usage on a scale from 1-6 (six being the highest).

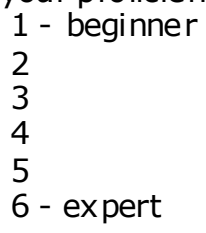

5. Rate your proficiency with Web-browsing and online technologies on a scale from 1-6 (six being the highest).

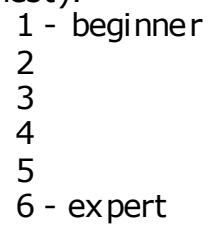

6. Where do you look for course announcements? (limit: 500 characters or approximately 75 words) 
Syndicated RSS Feeds

7. Do you know what an RSS feed is?

Yes

No

8. How often did you use the RSS feed for this course?

Several time per day

Once per day

A few times per week

Once per week

Less than once per week

Never

9. How often do you use other RSS feeds?

Several time per day

Once per day

A few times per week

Once per week

Less than once per week

Never

10. Rate the level of difficulty you had using the RSS feed for this course on a scale from 1-6 (one being very easy, six being very difficult).

$$
\begin{aligned}
& 1 \text { - beginner } \\
& 2 \\
& 3 \\
& 4 \\
& 5 \\
& 6 \text { - expert }
\end{aligned}
$$

11. How did you use the RSS feed? (in a web browser, with in instant messaging, RSS aggregator, other)? (limit: 500 characters or approximately 75 words)

12. Rate your prof iciency with RSS-related technologies on a scale from 1-6 (six being the highest).

$$
\begin{aligned}
& 1 \text { - beginner } \\
& 2 \\
& 3 \\
& 4 \\
& 5 \\
& 6 \text { - expert }
\end{aligned}
$$

13. Rate your knowledge of RSS-related technologies on a scale from 1-6 (six being the highest)

$$
\begin{aligned}
& 1 \text { - beginner } \\
& 2 \\
& 3 \\
& 4 \\
& 5 \\
& 6 \text { - expert }
\end{aligned}
$$

14. Rate the level of difficulty you have had using RSS feeds in the past on a scale from 1-6 (six being the highest)

$$
\begin{aligned}
& 1 \text { - beginner } \\
& 2 \\
& 3 \\
& 4 \\
& 5 \\
& 6 \text { - expert }
\end{aligned}
$$

15. What do you think about the integration of an RSS feed into this course? (limit: 500 characters or approximately 75 words) 
16. Which do you prefer for checking course announcements, checking the course homepage or using an RSS feed?

Course Homepage

RSS Feed

17. Is there another method, other than RSS feeds, that you would prefer for the delivery of course announcements? (limit: 500 characters or approximately 75 words)

18. Would you recommend that other courses offer an RSS feed for course announcements in addition to traditional means? (limit: 500 characters or approximately 75 words)

19. Do you feel that the RSS feed was an effective means of communicating course announcements? (limit: 500 characters or approximately 75 words)

20. What kind of course information do you feel is most appropriate for dissemination via the RSS feed? (limit: 500 characters or approximately 75 words)

21. If you did not use the RSS feed, why did you choose not to use it? (limit: 500 characters or approximately 75 words)

\section{Biographies}

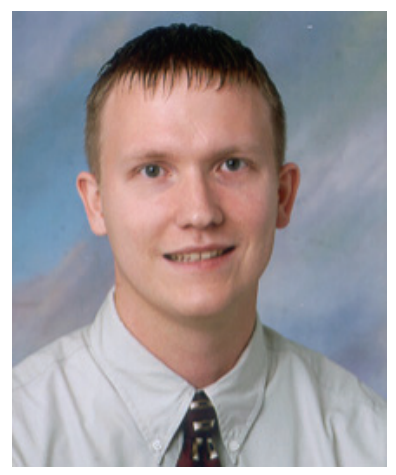

Ronald J. Glotzbach is an assistant professor for the interactive multimedia development area in the department of Computer Graphics T echnology at Purdue University's West Lafayette campus. Ronald's research interests include leading-edge technologies that expand the boundaries of dynamic and interactive content delivered and collaborated on via the graphical communication tool that is the web. Related interests include web-enabling software, dynamic content delivery methods, programming graphics, and integration of varying media into highly technological solutions. Research topics include: Dat abase design, theory, and application for use with dynamic content development and deployment; Automation of processes and tasks via the Web; Graphics applications in E-Commerce and E-Business; Dynamic content deployment to mobile devices.

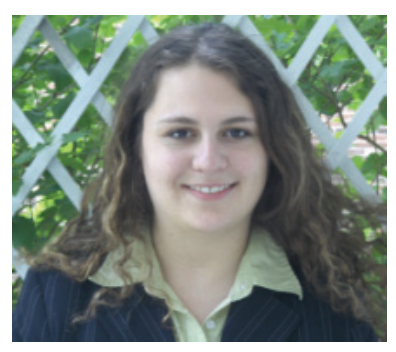

Dorina A. Mordkovich is a graduate student in the Department of Computer Graphics at Purdue University. Her focus is in web development, web programming, and database integration. Dorina's other interests lie in instruction and curriculum development and incorporation of existing technologies into the classroom.

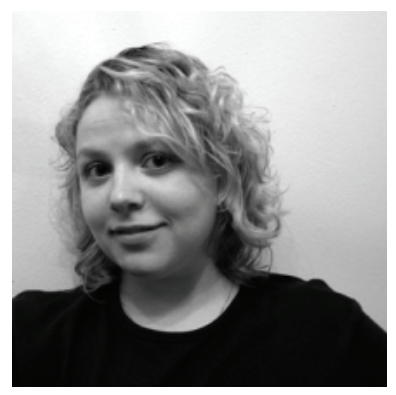

Jaime E. Radwan is currently employed as a Web Designer / Graphic Artist by Incredible Technologies in Arlington Heights, IL where she is responsible for the design and functionality of the company's websites and interfaces. She earned her B.S. in Digital Design from the University of Cincinnati's College of Design, Architecture, Art and Planning (DAAP) followed by her M.S. in Computer Graphics T echnology from Purdue University. 